\title{
Ethical behaviors and willingness to report misconduct in the public sector
}

\author{
Ho Phi Dinh ${ }^{a}$, Phuong V. Nguyen ${ }^{b, c^{*}}$, Thi Vu Anh Trinh ${ }^{b, c}$ and Tham Huy Pham ${ }^{\text {b,c }}$
}

${ }^{a}$ Phan Thiet University, Vietnam

${ }^{b}$ Center For Public Administration, International University, Vietnam

'International University, Vietnam National University Ho Chi Minh City, Vietnam

CH R O N I C L E

\section{Article history:}

Received: April 8, 2020

Received in revised format:

April 252020

Accepted: May 14, 2020

Available online:

May 14, 2020

Keywords:

Peer relationship

Ethical leadership

Fairness

Affective commitment

Public service motivation

Willingness to report

\section{A B S T R A C T}

This article concentrates on extending a theoretical framework by exploring employees' willingness to report unethical issues under the effects of ethical leadership, public service motivation, peer relationship, affective commitment, and fairness. By using structural equation modeling to analyze data collection from 320 public servants in Ho Chi Minh City, Vietnam, the results demonstrate that all the mentioned factors are positively correlated with willingness to report unethical issues in the context of the public sector, except for public service motivation. The findings open a potential path for future investigation of affective commitment and fairness as mediators that help to stimulate the behavioral reports of misconduct at workplaces. The new findings expand the literature in the public sector and suggest possible solutions to promote an energetically ethical environment.

\section{Introduction}

The decline in government trust across many nations has raised significant questions on the motives of public servants (whether they are self-interest driven or public interest-driven) and their accountability to achieve desired policy outcomes (Villoria et al., 2013). Surveyed employees in public organizations claimed the widespread unethical behaviors in their workplace (Kolthoff et al., 2010) and that they are unable to report unethical conduct due to fear of retaliation and resistance to take corrective actions (Caillier, 2015). Despite the severity of the inability to report misconduct in the public sector, very little literature has been conducted to address it. One branch of the study emphasized on public service motivation (PSM) as one predictor of willingness to report ethical problems (Brewer \& Selden, 1998; Caillier, 2015; Wright et al., 2016). The empirical result, however, is unclear due to the finding that PSM has no direct effect on the reporting behavior (Caillier, 2015), they call for further investigation. Another branch promoted the predicting role of ethical leadership (Hassan et al., 2014; Walumbwa \& Schaubroeck, 2009; Wright et al., 2016). Therefore, the current study aims to seek the how human resource implications for encouraging public servants' willingness to report ethical problems and promote ethical behaviors by testing the effects of PSM and ethical leadership and their potential mechanisms. Considering the significance of government trust and accountability, many public administration scholars have searched for possible practices to enhance ethical behavior in public organizations in terms of managerial perspectives and public employees' personal characteristics (Wright et al., 2016). On the one hand, regarding administrative practices, previous studies highlighted on the role of the ethical training program (Beeri et al., 2013), ethical leadership (Hassan, 2015; Hassan et al., 2014; Wright et al., 2016), and transformational leadership (Caillier, 2015). On the other hand, regarding personal characteristics, researchers explore employees' values and experiences (Cooper, 2004; Rohr, 1989). Moreover, some other studies investigate the role of PSM concerning ethical behaviors (Caillier, 
2015; Kwon, 2014). However, there is still little empirical support for the relationship. The current study aims to encourage ethical behavior (i.e., willingness to report) in public organizations by investigating PSM and its relation to ethical leadership, following the pioneering study of (Wright et al., 2016), which lacks empirical support.

To bridge these gaps, we raise the following research questions:

1. Do PSM and ethical leadership impact on willingness to report in the public sector?

2. What are the underlying mechanisms that can strengthen the impact of PSM and ethical leadership on willingness to report?

In seeking to answer the above questions, the public sector in Vietnam was chosen as the context since the sector landscape is ideally reflected in the study with dominant characteristics of high collectivism and power distance. Supportive relationships between leaders and subordinates in a collective culture can help discourage them from committing detrimental conduct and orient them towards communal goals (Rowley et al., 2007). Meanwhile, subordinates in high power distance workplaces often experience and accept mistreatments as part of obeying the commands from their leaders, which may deter subordinates from voicing reports of misconduct due to their inferiority (Kwan et al., 2014). Thus, it is critical to evoke public servants' concerns for misconduct reporting by investigating the impact of ethical leadership and PSM and the underlying mechanisms, including peer relationships, affective commitment, and fairness.

In this study, we aim at extending the existing literature with knowledge of mechanisms that facilitate public servants to report ethical issues. The findings illustrate ethical leadership as a significant stimulator of PSM and employees' willingness to report misconduct. Although PSM is found to have no direct impact on the reporting behavior, affective commitment as a mediator strengthens the effect of PSM to encourage employees to report. Moreover, the result identifies fairness as a significant determinant of willingness to report and as a new mediator that intensifies ethical leadership-reporting behavioral relationships. The findings also suggest some managerial implications for human resource managers to practice in the public sector.

\section{Literature review and Hypotheses Development}

\subsection{Peer relationship and affective commitment}

Few studies have investigated the effects of peer relationships on the organizational outcomes although the connection of employees with peers is proposed to be equally important as with their superiors to the overall organizational performance (Caillier, 2017). Vietnamese with a high hierarchy of authority also represents an invisible gap in the intimate leader-subordinate relationships. Hence, regarding the fit of the theoretical framework, high-quality peer relationship is emphasized in this study. Affective commitment is considered as "the most used and validated" proxy for organizational commitment (Stazyk, Pandey, \& Wright 2011) and defined as "the sense of belonging and emotional attachment" (Meyer et al., 1993).

Peer relationships are considered more approachable than leaders because employees share more time and conversations with their peers than with their leaders (Louis et al., 1983). The importance of communication in a relationship is a prerequisite to stimulate commitment (Saleh, Ali, and Julian, 2013; Abeysekera and Wickramasinghe, 2012). In addition, employees are more attached to the organizations by the support of peers in terms of emotions and career development, which generates a sense of belongingness (Colbert et al., 2016). The previous finding claimed the importance of the linkage between commitment and peer relationships (Vardaman et al., 2016). Based on the literature, the first hypothesis is proposed:

$\mathrm{H}_{1}$ : Peer relationship has a positive effect on affective commitment.

\subsection{Affective Commitment and Public Service Motivation}

PSM is defined as "the tendency of an individual to respond to a specific motive in a public organization". (Perry \& Wise, 1990). Hall et al. (2014) found a positive association between PSM and organizational commitment. Similarly, we expect PSM to have a positive influence on affective commitment. Employees with high PSM may feel a sense of self-importance when empowered and involved in the policy-making process (rational motivation); a sense of consistency when their values match the organizational norms to maximize the public benefits (normative motivation); and a sense of belonging when they feel the job meaning to serve the public (affective motivation). Therefore, we suggest the second hypothesis:

$\mathrm{H}_{2}$ : Public service motivation has a positive effect on affective commitment.

Affective commitment has been identified as a predictor of several organizational outcomes (Markovic et al., 2015; Mayer et al., 2009). However, little literature investigated an important role in enhancing the willingness to report problems in public organizations. Hassan et al. (2014) attribute reason for not reporting misconduct to "fear of retaliation." One possible reason is that affective commitment provokes belongingness, which guarantees employees a sense of security to raise their voice on sensitive issues and report problems without fear of retaliation to protect the organization. Therefore, we suggest the following hypothesis: 
$\mathrm{H}_{3}$ : Affective commitment has a positive effect on the willingness to report problems.

Employees guided by public interests are stated to have more will to report unethical behaviors than those peers driven by personal interests, which directly contradicts their values (Wright et al., 2016). Moreover, employees with a high level of PSM prioritize the interests of others when it comes to reporting. Thus, they are more likely to report ethical misconduct even if exposed to retaliation (Brewer \& Selden, 1998). Unfortunately, inconsistent conclusions are drawn on the relationship between PSM and willingness to report. PSM is proposed to trigger employees' intention to report misconduct (Wright et al., 2016), whereas Caillier (2015) finds no direct relationship. Therefore, we suggest the following hypothesis:

$\mathrm{H}_{4}$ : Public service motivation has a positive effect on the willingness to report.

\subsection{Ethical Leadership, Public Service Motivation, and Willingness to Report Problems}

Previous studies indicate that ethical leaders must serve as ethical role models, exert fair treatment to other people, and actively promote ethical conduct among their subordinates (Brown et al., 2005; Brown \& Treviño, 2006). These scholars incorporate "honesty, integrity, and altruism" into ethical leaders' professional identities. By doing so, ethical leaders internalize the value of ethics and clarify the willingness to sacrifice their personal interests to serve the public. Additionally, role modeling of leaders is essential to motivate employees to follow (El Achi \& Sleilati, 2016), evidenced by behaving ethically in compliance with organizational norms and treating others fairly (Brown et al., 2005; Brown \& Treviño, 2006). Besides, clear communication of ethical principles and, provision of ethical guidance, and supervision of ethical and unethical behaviors among subordinates are considered influential to the promote underlying ethical message (Brown \& Treviño, 2006). Consequently, ethical leadership is supported to enhance PSM (Wright et al., 2016). Therefore, hypothesis 5 was developed:

\section{$\mathrm{H}_{5}$ : Ethical leadership has a positive effect on public service motivation.}

Fear of retaliation may act as a major refrain to the report of the unethical. Ethical leadership is proposed to reduce the retaliation fear by creating a safe organizational climate where employees feel free to discuss and report ethical misconduct without the fear of their interests being harmed (Walumbwa \& Schaubroeck, 2009; Wright et al., 2016). Social learning theory proposed the important role model of ethical leaders by behaving according to norms so that subordinates can observe and follow (Mayer et al., 2009). Consequently, subordinates learn from their role models what can be recognized as unethical to avoid and report misconduct to their superiors (Hassan et al., 2014). Therefore, we suggest the following hypothesis:

$\mathrm{H}_{6}$ : Ethical leadership has a positive effect on the willingness to report.

\subsection{Ethical leadership and Fairness and Willingness to Report Problems}

Hassan et al. (2014) believe that ethical leaders consider the well-being of others as well as the moral impact of their decisionmaking. First, ethical misconduct reflects contradictory values to what ethical leaders should hold, which distorts subordinates' perspective of their ethical leaders' identities. Second, leaders must create a working climate where ethics serves as a compass that defines the rule of fairness in organizational activities (Pedersen et al., 2017). Unethical issues may violate the rule of fairness by leaders' special treatments to serve the personal interests of some specific subordinates and not others. In addition, previous research has examined the role of fairness in the public sector in correlation with ethics (Cecez-kecmanovic \& Marjanovic, 2018) and public hiring (Pedersen et al., 2017). However, no attention has been paid on the relationship between fairness and employee willingness to report. Hence, this study is the first one to explore this relationship. We suggest that ethical leaders exert fair treatments gaining employees confidence in raising their voices. The increased level of ethics encourages employees to create a fair working climate where unethically special treatments to an individual over the public interests should be eliminated. Plus, fairness implies that there should be no invisible power that hinders employees from protecting the right thing and reporting misconducts, which increases the tendency of willingness to report. Therefore, we suggest the following hypotheses:

H7: Ethical leadership has a positive effect on fairness.

H8: Fairness has a positive effect on the willingness to report.

The literature review illustrates a further necessity for extending theoretical frameworks, providing more evidence from empirical study, and suggesting practical implications regarding ethical behaviors and willingness to report unethical issues in the public sector. The previous literature shows the different effects of public service motivation but has not provided a sufficient basis for a comprehensive model that regards both antecedents and consequence of public service motivation and willingness to report misconduct in the public sector. Figure 1 presents an integrated theoretical model considered as an initial point in the Vietnamese public sector. 


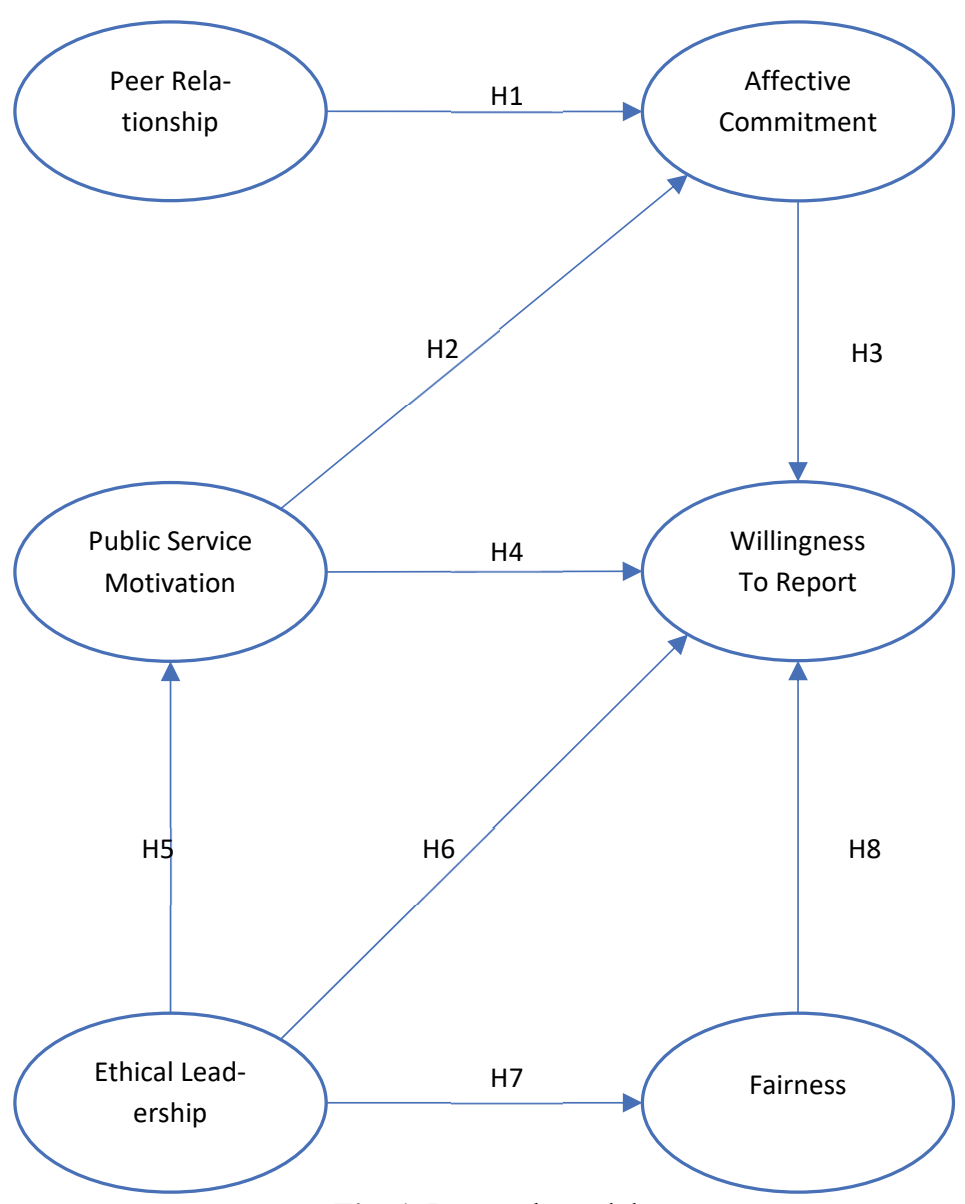

Fig. 1. Research model

\section{Methodology}

\subsection{Measures}

Respondents are requested to evaluate the questionnaire based on the Likert-scale ranging from 1 (strongly disagree) to 5 (strongly disagree). First, the 8-item scale of ethical leadership is adapted by Wright et al. (2016). Second, an affective commitment was evaluated on a 5-item measurement from the previous study of Wright et al. (2016) and Caillier (2017). Third, the PSM scale is constructed with three original items from Wright et al. (2016) and Pedersen et al. (2017) reflecting internal incentives. We also added three self-developed items which concern job promotion as a potential external motivator. Forth, the 4-item scale of (Wright et al., 2016) measures fairness in the decision-making process with one additional item "uphold ethical and moral standards." Fifth, based on the observed characteristics of the high-quality relationship among peers, we developed the measurement scale including information from peers (1) helps in learning task and social information, (2) aids in making sense of the organizational environment, (3) helps in characterizing cultural issues in organizations. Finally, after the group discussion with experts, we are suggested to add two more problems "dubious process" and "personal conflicts" besides "ethical problems" to assess employees' willingness to report problems, which are emblematic moments in the public sector.

\subsection{Data collection}

A total of 350 public servants in Ho Chi Minh City, Vietnam was asked to complete the questionnaire, including demographic information and 30 questions representing six critical factors in the research model. We use the back-translation approach of Brislin et al. (1973) to ensure the equivalent meaning of the questionnaires between the English and Vietnamese versions. After a five-month sampling period from July 2018 to November 2018, 320 valid samples were collected (usable response rate of $91 \%$ ), which meets the required sample size. Specifically, the female accounted for $60.6 \%$ out of the total correspondents, outnumbering the male correspondents with $39.4 \%$. The majority of the surveyed employees belonged to the $26-45$ age group $(84.6 \%)$ and had the education level of bachelor's degree $(86.6 \%)$. Besides, all correspondents had been working for 
the public sector for 1-10 years (64.4\%); however, there were many experts in the field with 10-30 years of experience taking up for $35.6 \%$, which confirmed the validity of the data.

\section{Results}

Factor loading is suggested to be of statistical significance when the figure is above 0.5 (Hair et al., 1998). As a result, we eliminated AC1 and PSM3 out of the framework since the factor loadings fell short of the requirement. Table 1 displays an illustration of qualified Exploratory Factor Analysis (EFA) loadings and Cronbach's alphas of the remaining 28 measurement items for further analysis.

Table 1

Data description and reliability analysis

\begin{tabular}{|c|c|c|c|c|c|}
\hline Construct & Items & EFA & Alpha & CR & AVE \\
\hline Ethical Leadership (EL): My supervisor... & & & 0.929 & 0.928 & 0.618 \\
\hline keeps his/her actions consistent with his/her stated values & EL1 & 0.643 & & & \\
\hline shows a strong concern for ethical and moral values & EL2 & 0.697 & & & \\
\hline sets an example of ethical behavior in his/her decisions and actions & EL3 & 0.679 & & & \\
\hline holds employees accountable for using ethical practices in their work & EL4 & 0.620 & & & \\
\hline insists on doing what is fair and ethical even when it is not easy & EL5 & 0.747 & & & \\
\hline opposes the use of unethical practices to increase performance & EL6 & 0.699 & & & \\
\hline regards honesty and integrity as important personal values & EL7 & 0.673 & & & \\
\hline communicates clear ethical standards for employees & EL8 & 0.635 & & & \\
\hline Affective Commitment (AC) & & & 0.883 & 0.870 & 0.629 \\
\hline I feel a strong sense of belonging to my unit & $\mathrm{AC} 2$ & 0.679 & & & \\
\hline I feel as if my unit's problems are my own & $\mathrm{AC} 3$ & 0.562 & & & \\
\hline I am willing to work harder to help the firm succeed & $\mathrm{AC} 4$ & 0.672 & & & \\
\hline I am proud to be working for my firm & AC5 & 0.709 & & & \\
\hline Public Service Motivation (PSM) & & & 0.834 & 0.703 & 0.563 \\
\hline I care deeply about benefiting others in society through my work & PSM1 & 0.752 & & & \\
\hline I am motivated to do well as I want to help others through my work & PSM2 & 0.565 & & & \\
\hline I feel motivated to do well as I want to get to a higher position & PSM4 & 0.648 & & & \\
\hline I won't be pleased if there is no work promotion & PSM5 & 0.725 & & & \\
\hline I'll be more satisfied to know that job promotion is highly available & PSM6 & 0.808 & & & \\
\hline Fairness (FN) & & & 0.907 & 0.903 & 0.652 \\
\hline are free of bias or favoritism? & FN1 & 0.698 & & & \\
\hline allow employees to express their views and concerns? & FN2 & 0.711 & & & \\
\hline allow employees to appeal the decisions? & FN3 & 0.640 & & & \\
\hline are based on accurate information? & FN4 & 0.706 & & & \\
\hline uphold ethical and moral standards? & FN5 & 0.622 & & & \\
\hline Peer Relationship (PR): & & & 0.908 & 0.908 & 0.767 \\
\hline helps in learning the task and social information & PR1 & 0.751 & & & \\
\hline aids in making sense of the organizational environment & PR2 & 0.694 & & & \\
\hline helps in characterizing cultural issues in organizations & PR3 & 0.770 & & & \\
\hline Willingness To Report: I feel comfortable reporting... & & & 0.880 & 0.880 & 0.711 \\
\hline ethical problems to upper management & WTR1 & 0.755 & & & \\
\hline process problems to upper management & WTR2 & 0.637 & & & \\
\hline personal conflict problems to upper management & WTR3 & 0.634 & & & \\
\hline
\end{tabular}

Notes: Loading items were extracted from the Maximum Likelihood with rotation method of Promax.

Source: Data collection

All values of Composite Reliability (CR) and Average Variance Extracted (AVE) displayed in Table 1 were respectively higher than 0.7 and 0.5 , satisfying convergent and discriminant validity requirements (Fornell \& Larcker, 1981). Table 2 illustrates that all CFA and SEM model fit indices are well within the acceptable standards (Hu \& Bentler, 1999). Table 3 presents the final results of testing the hypothetical model showing the standardized estimated coefficients, except for the relationship between PSM and willingness to report.

Table 2

Model fit indices in CFA and SEM

\begin{tabular}{ccc}
\hline Model fit indices & Thresholds & CFA \\
\hline CMIN/df & $\leq 2^{* *}, \leq 3^{*}$ & 1.887 \\
GFI & $\geq 0.9^{* *}, \geq 0.8^{*}$ & 0.882 \\
AGFI & $\geq 0.8^{*}$ & 0.479 \\
CFI & $\geq 0.9^{* *}$ & 0.855 \\
IFI & $\geq 0.9^{*}$ & 0.954 \\
RMSEA & $\leq 0.05^{* *}, \leq 0.08^{*}$ & 0.957 \\
\hline Notes: **excellent; *acceptable. & & 0.926 \\
\end{tabular}


Table 3

Hypothesis testing

\begin{tabular}{lccc}
\hline Hypothesis & Estimates & P-value & Result \\
\hline $\mathrm{H} 1 . \mathrm{PR} \rightarrow \mathrm{AC}$ & 0.330 & $* * *$ & Accepted \\
$\mathrm{H} 2 . \mathrm{PSM} \rightarrow$ AC & 1.082 & $* *$ & Accepted \\
$\mathrm{H} 3 . \mathrm{AC} \rightarrow$ WTR & 0.297 & ns & Accepted \\
$\mathrm{H} 4 . \mathrm{PSM} \rightarrow$ WTR & 0.100 & $* * *$ & Not accepted \\
$\mathrm{H} 5 . \mathrm{EL} \rightarrow \mathrm{PSM}$ & 0.374 & $* * *$ & Accepted \\
$\mathrm{H} 6 . \mathrm{EL} \rightarrow \mathrm{WTR}$ & 0.284 & $* * *$ & Accepted \\
$\mathrm{H} 7 . \mathrm{EL} \rightarrow \mathrm{FN}$ & 0.758 & $*$ & Accepted \\
$\mathrm{H} 8 . \mathrm{FN} \rightarrow$ WTR & 0.299 & Accepted & \\
\hline
\end{tabular}

Notes: $* * * p<0.001 ; * p<0.05 ;$ ns: non significant

Sources: Data collection

\section{Discussion}

\subsection{Contributions to the literature}

This study aims to investigate the determinants of employee willingness to report problems in public organizations. In line with the previous studies, ethical leadership is found to have a significant effect on encouraging employees to report unethical conduct (Brown et al., 2005; Hassan et al., 2014), and boosting PSM (Wright et al., 2016) in the public organizations. However, we found no direct impact of PSM on willingness to report, consistent with (Caillier, 2015) but contradictory to (Wright et al., 2016). The result, interestingly, directs us to a potential path of investigating the mediating factor, specifically affective commitment, that can strengthen the relationship between PSM and the will to report unethical behaviors. This finding is one of the major contributions of the current study, identifying an additional way to enhance the effect of PSM on willingness to report. One possible explanation is that the sense of security and belongingness urges public employees to report for the collective benefits of the organization they are effectively committed. Moreover, consistent with previous studies of (Colbert et al., 2016; Vardaman et al., 2016), peers are critical to enhancing affective commitment. We call for a potential future path of examining affective commitment as a mediator in correlation with positive work-related outcomes in the public sector. Consistent with the study of Pedersen et al. (2017), ethical leadership positively stimulate fairness in public organizations. This second major finding contributes to the literature review with our pioneering attempt to discover fairness as a potential determinant of willingness to report. We attribute the underlying reason to the perception that fairness highly appreciates the equitable benefits of every society member; thus, stimulates the likelihood of employees to report misconduct to ensure a fair working climate. The result also extends the existing literature with the final major contribution, proposing fairness as a mediator in the relationship between ethical leadership and willingness to report in the public sector, which needs further investigation.

\subsection{Implications}

The study enlightens the important factors that enhance employee willingness to report misconduct in public organizations, especially ethical leadership, as the most significant stimulator. Ethical leadership also acts as a driver of fairness and PSM, both of which, directly and indirectly, have a significant influence on the willingness to report. Hence, human resource management practices should focus on ethical leadership to create a workplace where employees feel free to raise their opinions on sensitive issues. Strong ethical conviction is a recommended feature that managers should consider during recruitment (Mayer et al., 2009). To incorporate ethics into the organizations, leaders should first clarify the ethical principles. Ethical leaders should act as a role model under the guidance of clarified principles, which strongly stimulate employees to follow and engage in work of conduct at workplaces. Ethics training and development programs for ethical leadership are highly advisable for each leader in designing, managing, and improvising with the appropriate practices for their organizations. Besides, daily conversations between leaders and employees are crucial in principles formulation and supervision process (Raisi, Amin, and Tahir, 2010) by welcoming guidance, signaling of open discussions, and attentive monitor of the practice of ethics in the organizations.

\section{Conclusion}

This study has highlighted the causal relationship between ethical leadership and willingness to report problems and the underlying mechanisms. The practice of ethical leadership has been found to be most influential in enhancing reports of misconduct compared to other factors in the study. Ethical leadership also acts as a strong driver of fairness and PSM, which are direct and indirect mechanisms by which ethical behaviors (for example, report of the unethical issues) are encouraged. More emphasis should be paid on the significant role of ethical leadership in correlation with ethical behaviors in public organizations. Our finding, which does not support the relationship between PSM and willingness to report, opens a promising path for future research of mediators, proposing the significant mediating effect of affective commitment in engaging employees in ethics discussions. Furthermore, fairness is explored as a potential determinant and mediator of willingness to report problems, which needs further investigation. Regarding the importance of ethical leadership in the framework, we suggest practices for human resource managers to establish an ethical and fair working climate in the public sector. 


\section{References}

Abeysekera, N., \& Wickramasinghe, A. (2012). Transforming nobody to somebody: Do transformational leadership and relationship marketing make a difference for sustainable marketing? International Journal of Trade and Global Markets, $5(1), 31$.

Beeri, I., Dayan, R., Vigoda-Gadot, E., \& Werner, S. B. (2013). Advancing ethics in public organizations: The impact of an ethics program on employees' perceptions and behaviors in a regional council. Journal of Business Ethics, 112(1), 59-78.

Brewer, G. A., \& Selden, S. C. (1998). Whistle blowers in the federal civil service: New evidence of the public service ethic. Journal of Public Administration Research and Theory, 8(3), 413-440.

Brislin, R.W., Lonner, W.J., \& Thorndike, R. M. (1973). Cross-cultural research methods. John Wiley and Sons.

Brown, M. E., \& Treviño, L. K. (2006). Ethical leadership: A review and future directions. The Leadership Quarterly, 17(6), $595-616$.

Brown, M. E., Treviño, L. K., \& Harrison, D. A. (2005). Ethical leadership: A social learning perspective for construct development and testing. Organizational Behavior and Human Decision Processes, 97(2), 117-134.

Caillier, J. G. (2015). Transformational leadership and whistle-blowing attitudes: Is this relationship mediated by organizational commitment and public service motivation? The American Review of Public Administration, 45(4), 458-475.

Caillier, J. G. (2017). The impact of high-quality workplace relationships in public organizations. Public Administration, 95(3), 638-653. https://doi.org/10.1111/padm.12328

Cecez-kecmanovic, D., \& Marjanovic, O. (2018). Reconfiguration of Information Flows by Public Sector IT Systems : The Question of Fairness and Ethics.

Colbert, A. E., Bono, J. E., \& Purvanova, R. K. (2016). Flourishing via workplace relationships: Moving beyond instrumental support. Academy of Management Journal, 59(4), 1199-1223.

Cooper, T. L. (2004). Big questions in administrative ethics: A need for focused, collaborative effort. Public Administration Review, 64(4), 395-407.

El Achi, S., \& Sleilati, E. (2016). The effect of coaching on employee performance in the human resource management field: The case of the Lebanese banking sector. International Journal of Trade and Global Markets, 9(2), 137-169.

Fornell, C., \& Larcker, D. F. (1981). Evaluating structural equation models with unobservable variables and measurements error. Journal of Marketing Research, 18(4), 39-50.

Hair, J. F., Black, W. C., Babin, B. J., Anderson, R. E., \& Tatham, R. L. (1998). Multivariate data analysis. Uppersaddle River. Multivariate Data Analysis (5th Ed) Upper Saddle River, 6.

Hall, D. T., Schneider, B., Nygren, H. T., Hall, D. T., Schneider, B., \& Nygren, H. T. (2014). Personal Factors in Organizational Identification. 15(2), 176-190.

Hassan, S. (2015). The importance of ethical leadership and personal control in promoting improvement-centered voice among government employees. Journal of Public Administration Research and Theory, 25(3), 697-719.

Hassan, S., Wright, B. E., \& Yukl, G. (2014). Does ethical leadership matter in government? Effects on organizational commitment, absenteeism, and willingness to report ethical problems. Public Administration Review, 74(3), 333-343.

Hu, L. T., \& Bentler, P. M. (1999). Cutoff criteria for fit indexes in covariance structure analysis: Conventional criteria versus new alternatives. Structural Equation Modeling, 6(1), 1-55. https://doi.org/10.1080/10705519909540118

Kolthoff, E., Erakovich, R., \& Lasthuizen, K. (2010). Comparative analysis of ethical leadership and ethical culture in local government: The USA, The Netherlands, Montenegro and Serbia. International Journal of Public Sector Management, 23(7), 596-612.

Kwan, S. S. M., Tuckey, M. R., \& Dollard, M. F. (2014). Dominant culture and bullying; Personal accounts of workers in Malaysia. In Psychosocial factors at work in the Asia Pacific (pp. 177-200). Springer.

Kwon, I. (2014). Motivation, discretion, and corruption. Journal of Public Administration Research and Theory, 24(3), 765794.

Louis, M. R., Posner, B. Z., \& Powell, G. N. (1983). The availability and helpfulness of socialization practices. Personnel Psychology, 36(4), 857-866.

Markovic, S., Iglesias, O., Jit, J., \& Vicenta, S. (2015). How does the perceived ethicality of corporate services brands influence loyalty and positive word-of-Mmouth ? Analyzing the roles of empathy, affective commitment, and perceived quality. Journal of Business Ethics, 154(2), 441-459.

Mayer, D. M., Kuenzi, M., Greenbaum, R., Bardes, M., \& Salvador, R. B. (2009). How low does ethical leadership flow? Test of a trickle-down model. Organizational Behavior and Human Decision Processes, 108(1), 1-13.

Meyer, J. P., Allen, N. J., \& Smith, C. A. (1993). Commitment to organizations and occupations: Extension and test of a threecomponent conceptualization. Journal of Applied Psychology, 78(4), 538.

Pedersen, M. J., Stritch, J. M., \& Taggart, G. (2017). Citizen perceptions of procedural fairness and the moderating roles of 'belief in a just world' and 'public service motivation' in public hiring. Public Administration, 95(4), 874-894.

Perry, J. L., \& Wise, L. R. (1990). The motivational bases of public service. Public Administration Review, 367-373.

Rohr, J. A. (1989). Ethics for bureaucrats: an essay on law and values. New York: M. NY: Marcel Dekker.

Rowley, C., Quang, T., \& Warner, M. (2007). To what extent can management practices be transferred between countries?: The case of human resource management in Vietnam. Journal of World Business, 42(1), 113-127.

Saleh, M. A., Ali, M. Y., \& Julian, C. C. (2013). Importer commitment drivers and their impact on performance: a resourcebased perspective. International Journal of Trade and Global Markets, 6(2), 123-140. 
Vardaman, J. M., Allen, D. G., Otondo, R. F., Hancock, J. I., Shore, L. M., \& Rogers, B. L. (2016). Social comparisons and organizational support: Implications for commitment and retention. Human Relations, 69(7), 1483-1505.

Villoria, M., Van Ryzin, G. G., \& Lavena, C. F. (2013). Social and political consequences of administrative corruption: A study of public perceptions in Spain. Public Administration Review, 73(1), 85-94.

Walumbwa, F. O., \& Schaubroeck, J. (2009). Leader personality traits and employee voice behavior: mediating roles of ethical leadership and work group psychological safety. Journal of Applied Psychology, 94(5), 1275.

Wright, B. E., Hassan, S., \& Park, J. (2016). Does a public service ethic encourage ethical behaviour? Public service motivation, ethical leadership and the willingness to report ethical problems. Public Administration, 94(3), 647-663. https://doi.org/10.1111/padm.12248

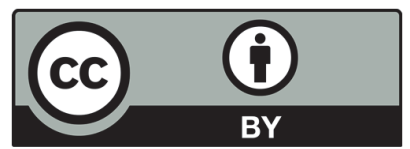

(C) 2020 by the authors; licensee Growing Science, Canada. This is an open access article distributed under the terms and conditions of the Creative Commons Attribution (CC-BY) license (http://creativecommons.org/licenses/by/4.0/). 